\title{
REVIEW
}

\section{Room-temperature multiferroic magnetoelectrics}

\author{
James F Scott \\ A short review is given of the recent work on single-phase crystals that are ferroelectric and ferromagnetic at or near room \\ temperature. $\mathrm{BiFeO}_{3}$ is mentioned only briefly, because it has been reviewed in detail elsewhere very recently; emphasis instead \\ is on copper oxide, perovskite oxides with mixed B-site occupancy (such as $\mathrm{Pb}\left(\mathrm{Fe}_{1 / 2} \mathrm{Ta}_{1 / 2}\right)_{\mathrm{x}}\left(\mathrm{Zr}_{\mathrm{y}} \mathrm{Ti}_{1-\mathrm{y}}\right)_{1-\mathrm{x}} \mathrm{O}_{3}$ and related $\mathrm{Nb}$ and \\ W compounds), Fe-, Co-, and Mn-based Aurivilius-phase oxides and hexaferrites. \\ NPG Asia Materials (2013) 5, e72; doi:10.1038/am.2013.58; published online 22 November 2013
}

Keywords: Ferroelectrics; magnetoelectrics; multiferroics

\section{INTRODUCTION}

Multiferroics are usually defined as single-phase crystals exhibiting at the same temperature and pressure both ferromagnetism (or antiferromagnetism) and ferroelectricity (or antiferroelectricity). As most ferroelectrics are also ferroelastic ${ }^{1}$ (hysteretic stress-strain relationships), the 'multi-ferro' label often includes three coupled order parameters. (As a peripheral comment, we note that it is necessary and sufficient ${ }^{2}$ for a ferroelectric to be ferroelastic if its phase transition changes the crystal class-for example, from orthorhombic to tetragonal-treating hexagonal and trigonal as a single super-class. Examples of nonferroelastic ferroelectrics include $\mathrm{KTiOPO}_{4}$ and $\mathrm{LiNbO}_{3}$, whose ferroelectric transitions are, respectively, orhorhombic-orthorhombic and trigonal-trigonal.)

The interest in multiferroics at present is growing rapidly, and the interest is twofold: from a fundamental point of view the coupling between spins and lattices in crystals-between magnetism and ferroelectricity and/or structural phase transitions-has been recognized as complex and fascinating for several decades, generally requiring low-symmetry materials that were carefully avoided in earlier days of solid state theory. A good reason why it is presented in the elegant work by Schmid and Trooster ${ }^{3}$ on the boracites: These materials (for example, nickel-iodine boracite) are multiferroic only at cryogenic temperatures and grow in needle-like structures, making them impractical for commercial device applications; and theoretically they exhibit low symmetry (monoclinic or triclinic) and have as many as 96 atoms per unit cell, making them theoretically formidable. Despite these drawbacks, multiferroics present a possible avenue for the next generation of computer digital memories, combining at least in principle, the high-speed and low-power consumption ${ }^{4,5}$ of a ferroelectric random access memory (FRAM) with the nondestructive READ operation of a magnetic RAM. We discuss below why these goals will not be easy to achieve in commercial products: The most serious problems are operational temperature (most multiferroics operate well below ambient) and magnitudes of magnetization (all multiferroics with reasonably high operating temperatures are weak ferromagnets—canted antiferromagnetswhereas a strong ferromagnet is desired), and the switched polarization is also extremely weak. The polarization in most multiferroics is so weak that authors measure it in $\mathrm{nCm}^{-2}$ rather than the older customary $\mu \mathrm{Ccm}^{-2}$. Keep in mind that equally good SI units would be Chectare $^{-1}$ for these multiferroics, a value far lower than the roughly $1 \mu \mathrm{Ccm}^{-2}$ required by a computer memory sense amplifier to discriminate between $+P$ (a ' 1 ') and $-P$ (a zero). We should also keep in mind that the so-called 'low' magnetic fields requisite to switch polarization $\mathrm{P}$ in a multiferroic are ca. $0.3 \mathrm{~T}$, orders of magnitude larger than the tiny $\mathrm{mT}$ values required in an magnetic RAM (MRAM); the latter can be provided by submicron-size coils or wires passing under each bit; however, that geometry is implausible for $0.1-1.0 \mathrm{~T}$ fields. In the final analysis, multiferroic RAMs will have to achieve breakthroughs in small size, weight and power to produce RAMs.

However, even if researchers fail to make commercial prototype RAMs in the near future, there might be other equally important memory applications for multiferroics, such as voltage-driven magnetic tunnel junctions, ${ }^{6}$ which require much less charge transport to function. In addition, the other competitors for the next generation of computer memories all have their own problems: ferroelectric nanotubes $^{7-16}$ are mechanically not very robust nor easy to manufacture with high yields; phase-change memories ${ }^{17}$ have a small operating temperature range unsuited for either military or automotive specifications and too large a thermal budget; however, Samsung has had a $512-\mathrm{Mb}$ phase-change random access memory (PRAM) in production since 2006. MRAMs ${ }^{18}$ have problems with cross-talk if not isolated bit-by-bit with space-demanding pass-gate transistors, which are undesirable with respect to cost and 'footprint' size on the chips; however, MRAMs are also good commercial memories with Everspin producing a $4-\mathrm{Mb}$ part. Nonvolatile MRAMs have been on the market since 2005. Slower than SRAM 
(static RAM), MRAMs are orders of magnitude faster than EEPROMs. So although we can blithely suggest that multiferroics may be 'a future generation of RAMs', it may not be the 'next generation, and flash EEPROMs, SRAMs and DRAMs are safe for now, with PRAMs, MRAMs and ferroelectric FRAMs all in commercial production, albeit for limited niche markets.

It is not necessary for multiferroic materials to be magnetoelectric. For example, $\mathrm{BaMnF}_{4}$ and $\mathrm{BaNiF}_{4}$ appear to be ferromagnetic and ferroelectric at low temperatures and have a linear magnetoelectric coupling between polarization $P$ and magnetization $M$ that is offdiagonal, giving a free-energy term

$$
G(M, P, T)=\alpha_{j k} P_{j} M_{k},
$$

where $j$ is not equal to $k$.

In fact, $P$ and $M$ are nearly 90 degrees apart (about 81 degrees of arc in $\left.\mathrm{BaMnF}_{4}\right)$, maximizing the $P \times M$ Dzyaloshinskii-Moriya coupling. However, in $\mathrm{BaCoF}_{4}$, the spins flop to be parallel to $P$, and hence the linear magnetoelectric term in Equation 1 above vanishes (that is, $\mathrm{BaCoF}_{4}$ and $\mathrm{BaMnF}_{4}$ have different magnetic space groups, 2 and $2^{\prime}$ ). Similarly, not all magnetoelectric materials are ferromagnetic or ferroelectric (for example, $\mathrm{Cr}_{2} \mathrm{O}_{3}$ ). Most authors use 'magnetoelectric' to define a material in which Equation 1 is nonzero and 'multiferroic' to imply simultaneous ferromagnetism and ferroelectricity; however, many writers will ignore the requirement that ferroelectrics can be switched and thereby include pyroelectrics. This is a matter of convenience, as semiconducting ferroelectrics can be difficult to switch and are often well-known materials long before switching was demonstrated (for example, GeTe, $\mathrm{SnTe}, \mathrm{PbTe}$ ).

One might ask how large the magnetoelectric effect can be; that is, how big is $\alpha_{j k}$ in Equation 1? In this respect Brown et al. ${ }^{19}$ showed that under most conditions $\alpha$ is limited by the square root of the product of the magnetic and electric susceptibilities:

$$
\alpha\left[\chi_{\mathrm{M}} \chi_{\mathrm{E}}\right]^{1 / 2}
$$

But more recently Dzyaloshinskii ${ }^{20}$ has shown that this limit can be violated in systems with more than one magnetic phase; a counter example might be if $\mathrm{Cr}_{2} \mathrm{O}_{3}$ became ferromagnetic and/or ferroelectric at lower temperatures. In real situations, $\alpha$ is much less than the upper limit in Equation 2 anyway; this is not the problem-the problem is that $M$ is much too small in Equation 1 for good devices, not that $\alpha$ is too small, (typical values of $\alpha$ in SI units are $c a \cdot 10^{-9}$ $10^{-11} \mathrm{~s} \mathrm{~m}^{-1}$ ), and this arises because almost all muiltiferroics are weak canted ferromagnets (with exceptions like $\mathrm{EuTiO}_{3}$ functioning only at cryogenic temperatures). Thus the present aim is to discover strong ferromagnets that are ferroelectric at room temperature, not larger magnetoelectric coupling constants.

\section{MATERIALS AND METHODS}

For the reasons described above, we want to have large switched polarizations and/or magnetizations, operating temperatures at or near ambient, low coercive voltages or magnetic fields, and of course other simpler criteriarobust, cheap chemicals, non-toxic (both worker-safety and environmental waste disposal concerns), and compatible with typical Si processing in a fabrication line ('Fab'). Below we consider the present state of play with four possible contenders: (a) $\mathrm{CuO}$, (b) perovskite Fe-containing oxides, (c) Aurivilius layer-structure oxides, and (d) manganese hexaferrites. These four families have research that is led at present, respectively, in Oxford, in a Puerto Rico-Cambridge-Belfast collaboration now, including Delhi; in Cork, Ireland and in Japan.

Much more work has been carried out on $\mathrm{BiFeO}_{3}$ since the seminal work from Ramesh's group, ${ }^{21}$ but this material has been reviewed extensively elsewhere ${ }^{22}$ and will be mentioned only in passing.

$\mathrm{BiFeO}_{3}$, especially in thin-film form, is a good ferroelectric and a weak ferromagnet up to several hundred degrees above room temperature. Discovered by Smolenskii and Yudin ${ }^{23}$ in Leningrad in the 1960s, it lay rather dormant for 45 years until it was shown to have improved properties in thin-film form. It has had about 10000 publications devoted to it in the past decade and remains the leading candidate for room-temperature multiferroic single-phase devices. However, it is far from perfect: its magnetization is too small for many applications, and its dielectric loss and leakage current too large, despite efforts to dope it with various elements. ${ }^{24-26}$ Its limitations in fact provide much of the motivation for the present review.

\section{Copper oxide}

Background. Copper oxide was first proposed as a multiferroic magnetoelectric device by Kimura et al. ${ }^{27}$ in 2008 . More recently, extensive studies have been reported by the Oxford group. ${ }^{28-30}$

Structure and properties:. The lattice structure of $\mathrm{CuO}$ is illustrated in Figure 1 and its magnetic cycloidic spin arrangement in Figure 2. $\mathrm{CuO}$ is an extremely interesting multiferroic because of its structural simplicity with only two formula groups per primitive cell and its transition temperatures; operating up to $230 \mathrm{~K}$ is very unusual for a multiferroic whose polarization $P$ is driven by a spin cycloid. Although $230 \mathrm{~K}$ is a relatively high temperature for a multiferroic, $\mathrm{CuO}$ has two important drawbacks that disqualify it from most device embodiments: (1) it operates over a narrow temperature range from 213 to $230 \mathrm{~K}$; this is at best inconvenient, and $230 \mathrm{~K}$ is less than room temperature, except in places like Yakutsk or Antarctica (however, operations in a space satellite might be possible; and $230 \mathrm{~K}$ is certainly above liquid nitrogen temperature); and (2) the polarization induced by a magnetic field, as in other cycloidic magnets, is much too small for RAMs or most device application.

The main interest at present in $\mathrm{CuO}$ is the evidence that it may exhibit toroidal moments and that these arise from orbital (not spin) currents, as diagrammed in Figure 3 below. However, even this is very controversial, with Joly et al. ${ }^{31}$ reinterpreting the Oxford data in simpler terms of birefringence. In addition to the pure physics interest in such phenomena, $\mathrm{CuO}$ has two other very attractive properties: its diatomic lattice is more amenable to theoretical modeling than are the complex structures of hexaferrites or Aurivilius layer a

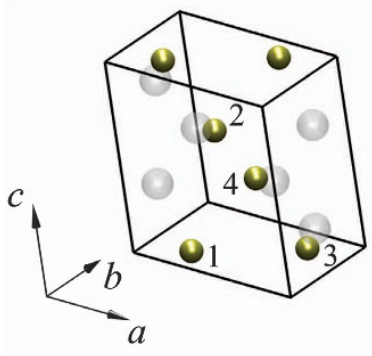

b

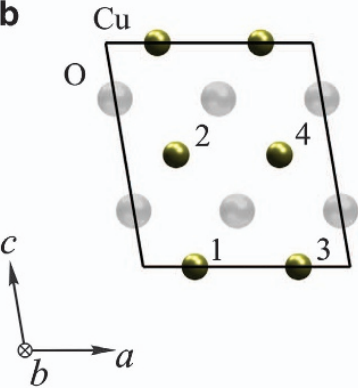

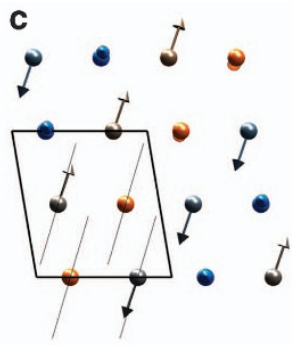

Figure $1(\mathbf{a}, \mathbf{b})$ Crystallographic structure of $\mathrm{CuO}^{28}$ (c) Magnetic structure of $\mathrm{CuO}^{28}$ 


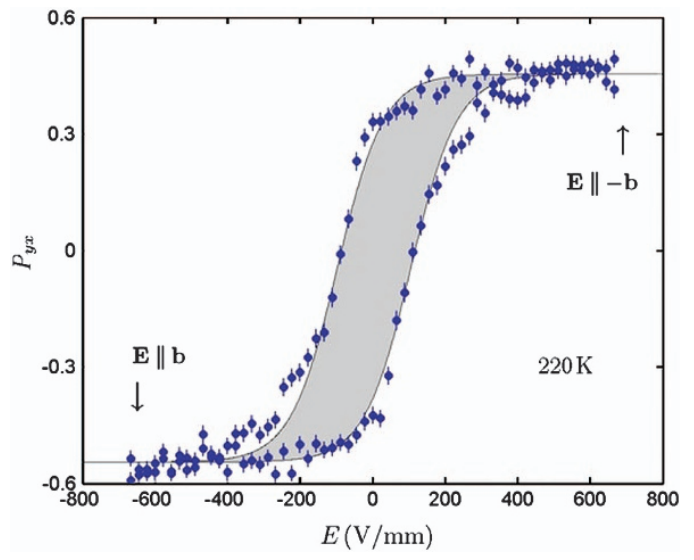

Figure 2 Magnetic $\mathrm{M}(\mathrm{H})$ hysteresis in $\mathrm{CuO}$.
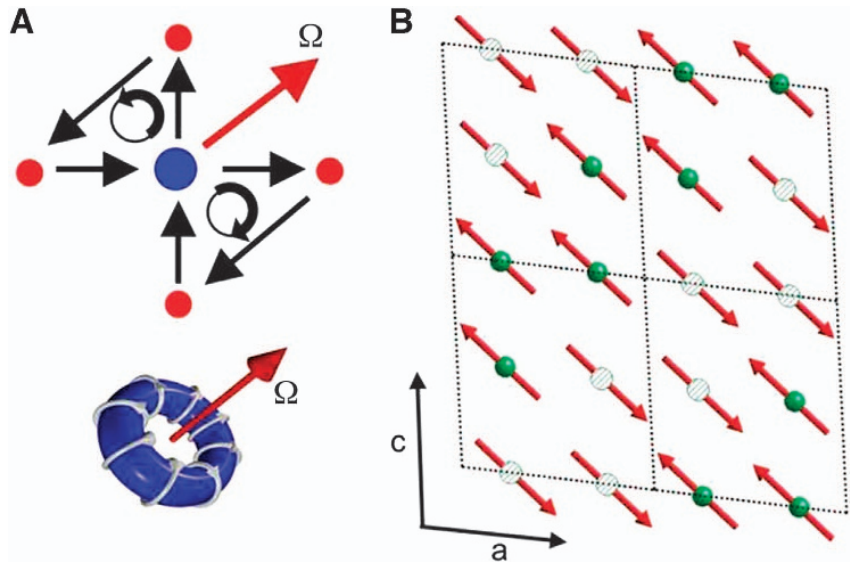

Figure 3 CuO diagram showing orbital loops. ${ }^{29}$ (A) real-space diagram, showing orbital current loop for toroidal ordering; (B) atomic-scale local magnetization directions.

structures discussed below; and from a device standpoint, its multiferroic properties can be extended from $230 \mathrm{~K}$ to above room temperature via application of hydrostatic pressure (A. Boothroyd, private communication).

It is also important to note that multiferroic switching in $\mathrm{CuO}$ is not symmetric in $E$ and $H$ : That is, one cannot switch electric polarization and domains with applied magnetic field, whereas it is relatively easy to do the converse and switch magnetic domains with electric fields. This was emphasized by Babkevich et al. ${ }^{28}$ and arises because the magnetism that couples to $E$ is cycloidic and not homogeneous; hence applying a homogeneous field $H$ is not the same as applying a field $E$. Fortunately, this is exactly the situation desired for a nondestructive-readout multiferroic FRAM; in that case, one wishes to perform WRITE, ERASE/REWRITE operations on the memory state $+M$ or $-M$ with a short voltage pulse, and READ operations by monitoring the magnetization state without switching. I emphasize this because the lead-iron-tungstate family discussed in a section below exhibit the converse-switching of $P$ with applied magnetic field $H$, and this is less optimum for memory device embodiments.

Lead-iron perovskites: $\mathrm{PbFe}_{1 / 2} \mathrm{Ta}_{1 / 2} \mathrm{O}_{3} / \mathrm{PbZr}_{\mathrm{x}} \mathrm{Ti}_{1-\mathrm{x}} \mathrm{O}_{3}, \mathrm{PbFe}_{1 / 2}$ $\mathrm{Nb}_{1 / 2} \mathrm{O}_{3} / \mathrm{PbZr}_{\mathrm{x}} \mathrm{Ti}_{1-\mathrm{x}} \mathrm{O}_{3}$, and $\mathrm{PbFe}_{2 / 3} \mathrm{~W}_{1 / 3} \mathrm{O}_{3} / \mathrm{PbZr}_{\mathrm{x}} \mathrm{Ti}_{1-\mathrm{x}} \mathrm{O}_{3}$ Background. Mixed perovskites of $\mathrm{PbFe}_{1 / 2} \mathrm{Ta}_{1 / 2} \mathrm{O}_{3}$ ('PFT'), $\mathrm{PbFe}_{1 / 2} \mathrm{Nb}_{1 / 2} \mathrm{O}_{3}$ ('PFN') and $\mathrm{PbFe}_{2 / 3} \mathrm{~W}_{1 / 3} \mathrm{O}_{3}$ ('PFW') with $\mathrm{PbZr}_{1-\mathrm{x}} \mathrm{Ti}_{\mathrm{x}} \mathrm{O}_{3}$ ('PZT') have been under study for several years in a San Juan-Cambridge-Belfast collaboration that now includes Delhi. ${ }^{32-40}$ The reason is shown in the Venn diagram in Figure 4. Each of the Fe-compounds is ferromagnetic at modest temperatures

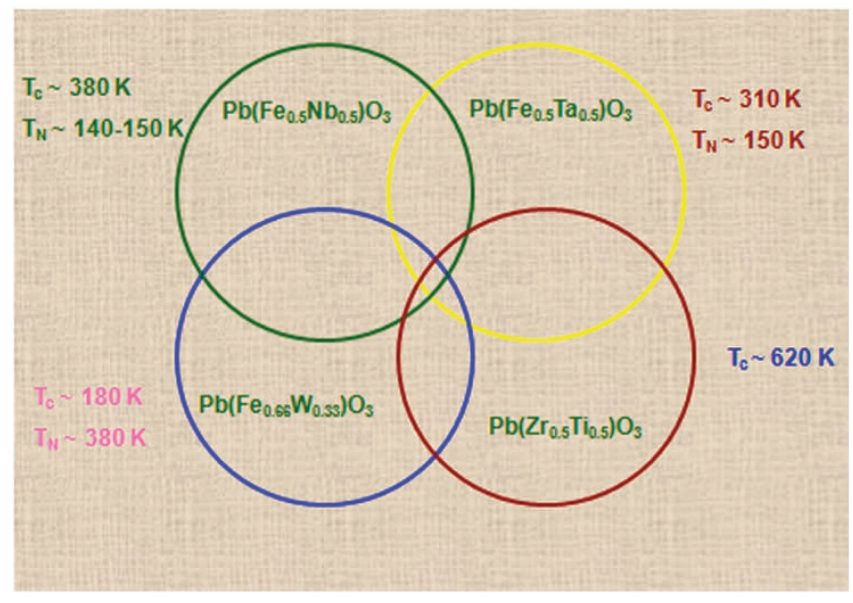

Figure 4 Venn diagram showing overlap of perovskite structures obtainable as single-phase multiferroics from $\mathrm{PZT}$ and $\mathrm{Pb}_{2} \mathrm{FeXO}_{6}(\mathrm{X}=\mathrm{Ta}, \mathrm{Nb} . \mathrm{W}) .{ }^{52}$

and ferroelectric at low temperatures. Each is structurally similar to (lattice constants) PZT and chemically compatible with PZT; that is, it is easy to form single-phase compounds with these four materials, which have ferroelectric Curie temperatures above ambient and have some residual ferromagnetism.

The long-range magnetism is that of canted (weak) ferromagnetic character, and it persists until $c a .400 \mathrm{~K}$ because of spin clustering. ${ }^{41-44}$ This has been well studied in pure PFN via magnetic resonance. Such cluster systems are not readily amenable via conventional density functional technique theory but might be suited to the type of calculation published by Bersuker and colleagues. ${ }^{45}$ From an experimental point of view, these are very attractive, as they are simple perovskite oxides and can be processed by all known bulk and film methods: ball-milling, sputtering, sol-gel spin-on, pulsed laser deposition, molecular beam epitaxy, and so on.

PFW. The PFW/PZT system was studied in some detail both theoretically and experimentally ${ }^{31-33}$ and exhibits a polarization $P(H)$ that is strongly dependent upon magnetic field $(H)$, collapsing abruptly for $H$ near $1.0 \mathrm{~T}$ (Figure 5). However, the data on dielectric loss $\varepsilon^{\prime}(H)$ (Figure 6) show that this is because $H$ changes the response time of the system, and hence this is a purely relaxational dynamic effect. Model calculations ${ }^{33}$ suggest that there is no bilinear $\alpha_{\mathrm{ij}} P_{\mathrm{i}} M_{\mathrm{j}}$ magnetoelectric coupling, but that all interaction between $P$ and $H$ is via magnetostriction $b M^{2} S^{2}$ plus electrostriction $d P^{2} S^{2}$ and piezoelectricity $d_{\mathrm{ijk}} P_{\mathrm{i}} S_{\mathrm{jk}}$. This can produce a useful room-temperature device in which $+P$ switches to zero (not to $-P$ ), but it is not strictly a multiferroic magnetoelectric. Concommitant with the change in $P(H)$ is a very large change in the frequency- and temperature-dependent dielectric loss $\varepsilon^{\prime}(T, H, f)$.

The key equation from the striction theory of Pirč et al. ${ }^{34}$ is that the imaginary part of the dielectric constant $\varepsilon^{\prime \prime}(T, H)$ peaks at a frequency $f_{0}$ that decreases by approximately five orders of magnitude with increasing $H$, from ca. $\mathrm{MHz}$ at $H=0$ to a few $\mathrm{Hz}$ (and finally zero) at $H_{c}=c a .1 \mathrm{~T}$.

$$
f=f_{0} \exp \left[\left(-E_{\mathrm{a}}\right) / \mu_{\mathrm{B}}\left(H_{c}^{2}-H^{2}\right)\right]
$$

This is a Vogel-Fulcher Equation for a glassy relaxor in which the usual Vogel-Fulcher freezing temperature $T_{f}$ (and freezing energy $k_{T} T_{f}$ ) are replaced by the square of a critical field $H_{c}^{2}$, which is proportional to energy. $H_{c}$ depends upon temperature, but for PFW single-phase compounds with PZT, at $293 \mathrm{~K}, H_{c}=0.92 \mathrm{~T}$. The data in Figure 7 are in remarkable agreement with the unusual Equation 3 and therefore lend strong support to the model. The model assumes values for magnetostrictive tensor components that are yet unmeasured, but these are of plausible magnitude in comparison with related materials. ${ }^{46}$ The theory estimates a numerical value of $H_{c}$ that is within a factor of two of that observed.

Another complication, however, is that the $\varepsilon^{\prime}(H)$ data are difficult to reproduce and depend strongly upon electroding, substrates, wire-bonding or painted contacts and anneal. ${ }^{47,48}$ (Zubko, P. personal communication) This is 


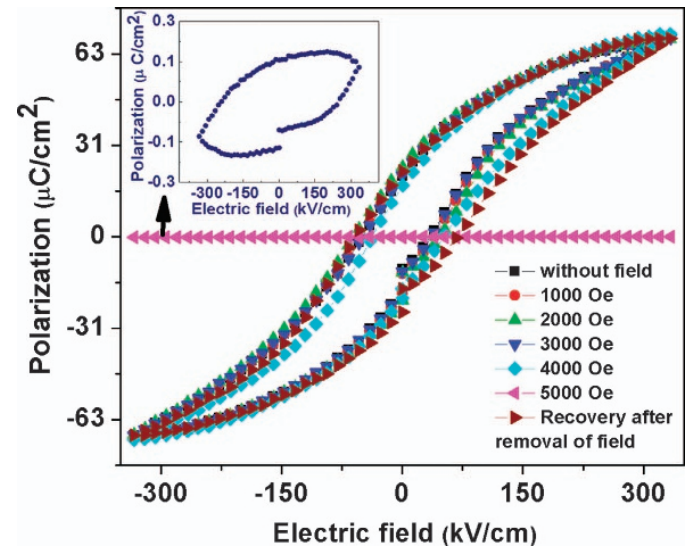

Figure 5 Electric polarization loops $P(f, H)$ in PFW/PZT at $T=293 \mathrm{~K}$ as a function of applied magnetic field $H$, showing abrupt disappearance near $H=1.0 \mathrm{~T}$.

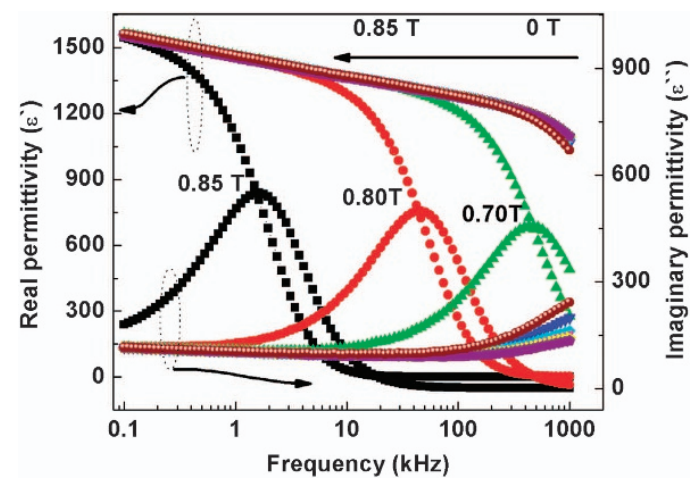

Figure 6 Dielectric loss in PFW/PZT versus frequency at different values of applied field $H$, showing collapse in response frequency (divergence in relaxation time $\tau) .{ }^{52}$

not surprising for a device, which works entirely on strain coupling. In addition, there are probably induction effects to consider: The striction model of Pirč et al. is for a perfect insulator and a perfect capacitor; but in the presence of charge injection, ferroelectrics acquire an inductance (Zubko, P. personal communication). Thus, depending upon sample processing and especially upon electroding, the data in Figure6 may require an equivalent LCR circuit and not just an RC time constant for complete analysis. Supporting the LCR model is the fact that the capacitance can become very small (near zero) as $H$ and $T$ change. What the studies on PFT/PZT do reveal is that some form of strong coupling can occur between polarization $P$ and magnetic field $H$ at temperatures well above the long-range ordering Neel temperature and that these couplings may be manifest most strongly in relaxation times-in the imaginary part of the dielectric response, not in the real part. In other work by the Ljubljana group, the magnetoelectric coupling constants were estimated for both $\mathrm{PFN}$ and its mixtures with $\mathrm{Pb}(\mathrm{Mg}, \mathrm{W}) \mathrm{O}_{3}$ (Zubko, P.. personal communication). Levstik et al. ${ }^{49}$ have also shown that the conductivity in these PFW/ PZT compounds is dominated by polaron hopping, which adds some insight into the magnetoelectric coupling.

The fact that PFT/PZT is a glassy relaxor is of special theoretical interest: Fischer and $\mathrm{Herz}^{50}$ show that spin glasses in acentric systems such as ferroelectrics cannot be Ising-like. Hence, these multiferroics must have more complicated domains.

PFT. $\mathrm{PbFe}_{1 / 2} \mathrm{Ta}_{1 / 2} \mathrm{O}_{3}$ was studied by itself and in artificial superlattice layer structures. ${ }^{5-53}$ Like PFN, it has weak ferromagnetism that is partly due to ferromagnetic spin clustering and partly due to Dzyaloshinskii-Moriya anisotropic-exchange canting. In combination with PZT, its properties are not

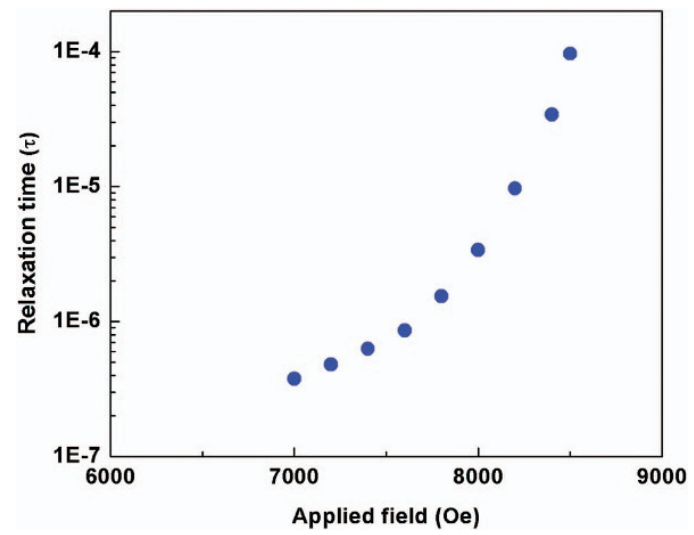

Figure 7 Theoretical polarization relaxation time $\tau(H)$ in the striction mode of Pirč et al. ${ }^{34}$

significantly dependent upon the $\mathrm{Zr} / \mathrm{Ti}$ ratio; and in fact, pure $\mathrm{PbTiO}_{3}$ works as well as PZT for most of these systems, as initially demonstrated with PFW. ${ }^{53}$

Switching in PFT/PZT single-phase nano-crystals was reported by Evans et al. ${ }^{54}$ as shown in Figure 8, using a submicron-diameter sample cut via focused-ion beam from a one-micron diameter grain in a bulk ball-milled ceramic. All tests show these samples to be single-phase, although under highresolution transmission electron microscopy some dark nano-spots were observed decorating the grain boundary. These are now known to be slightly Fe-rich nano-regions but not of a different phase.

The switching of electric polarization $P$ with applied $E$ in these specimens is routine and without much fatigue. More interesting is that the polarization can be switched at room temperature with a small magnetic field (experiments were done at $H=0.3 \mathrm{~T}$ and $1.8 \mathrm{~T}$ ).

However, the switching with $H$ manifests extremely rapid fatigue; the first switching of polarization $P$ with applied $H$ is fairly complete $(70-80 \%$ at $1.8 \mathrm{~T}$ ), but the second switch is only $c a .25 \% P$, and subsequent field reversals switch negligible amounts of polarization. ${ }^{54}$ This implies either that the magnetically switched electric domains are somehow more easily pinned or that another mechanism is involved, possibly involving the nested ferroelastic twins and magnetostriction. One can switch from $+P$ to $-P$ (a large value of ca. $60 \mu \mathrm{C} \mathrm{cm}^{-2}$ ). This is $1000 \times$ greater than in $\mathrm{CuO}$, and well above the requisite value for RAM sense amplifiers and discriminators. But in order to switch back from $-P$ to $+P$ with applied $H$, one must 'scramble' the ferroelastic nano-domains nested within each submicron ferroelectric domain (shown as the feathery structures in the TEM Figure 9). The model proposed ${ }^{55}$ is as follows:

Application of an external electric field $E$ poles the ferroelectric polarization $P$ but scrambles the underlying ferroelastic strain $S$. This is because perovskite oxides have not just $d_{33}$ piezoelectric constants (which would pole the strain along the $\mathrm{z}$ axis normal to the electrodes) but large $d_{31}$ also, which cause the strain to tilt away from $\mathrm{z}$ toward $\mathrm{x}$ (or $\mathrm{y}$ ). Application of magnetic fields $+H>0.2 \mathrm{~T}$ pole the ferroelastic strain via magnetostriction to lie along $\mathrm{z}$ and produce switching of $+P$. But a subsequent application of $-H$ does not switch the polarization back to $-P$, because the interaction is biquadratic $M^{2} S^{2}$; it is necessary to have an intervening $E$ field to re-scramble the ferroelastic strain alignment. Thus at present we tentatively conclude that magnetoelectric switching in PFT/PZT single-phase multiferroics is not due to bilinear magnetoelectric interaction of form $\mathrm{P} \times \mathrm{M}$ and that $E$ fields and $H$ fields are not at all equivalent switching fields. Instead, switching is quadratic in $M$ (similar to $\mathrm{CuO}$ ), and operates via magnetostriction (similar to PFW/PZT).

If this is correct, it will limit device applications severely: Strain interactions are subsonic, and hence the device may be too slow for a computer memory. And the quadratic dependence upon $H$ will necessitate a complex pulse sequence for rewrite operations.

The arguments about magnetostriction creating strain (and hence polarization) are subtle. At ambient temperature and pressure, $\mathrm{Pb}\left(\mathrm{Fe}_{1 / 2} \mathrm{Ta}_{1 / 2}\right)_{\mathrm{x}}$ $\left(\mathrm{Zr}_{y} \mathrm{Ti}_{1-y}\right)_{1-x} \mathrm{O}_{3}$ crystallizes in an orthorhombic structure of symmetry 
a

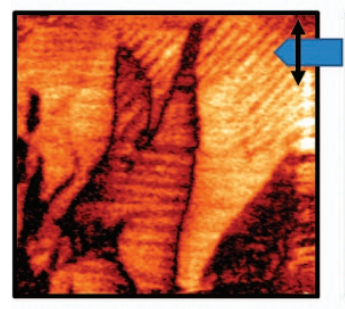

Before magnetic field
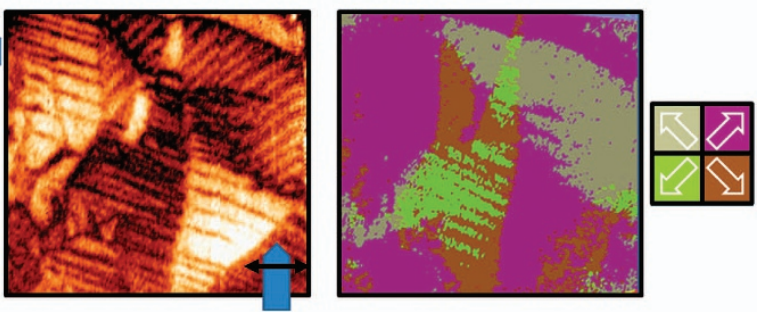

b

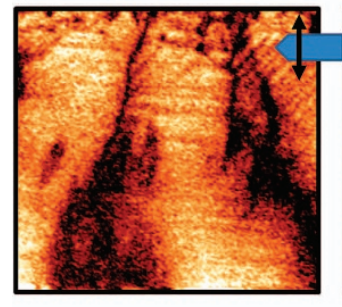

After $18 \mathrm{kOe}$ field
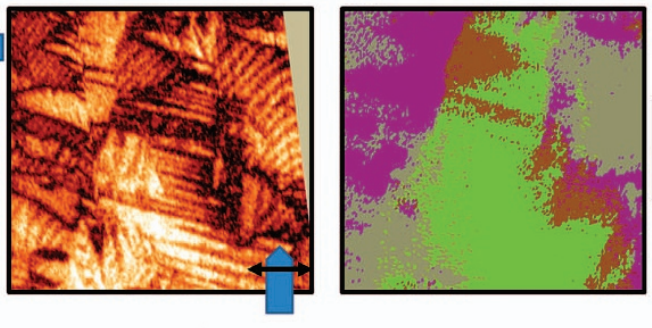

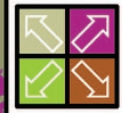

Figure 8 Real-space force microscopic images of electric polarization switching at $T=295 \mathrm{~K}$ with applied magnetic field $H=1.8 \mathrm{~T}$ in PFT/PZT single-phase crystals. ${ }^{53}$

a

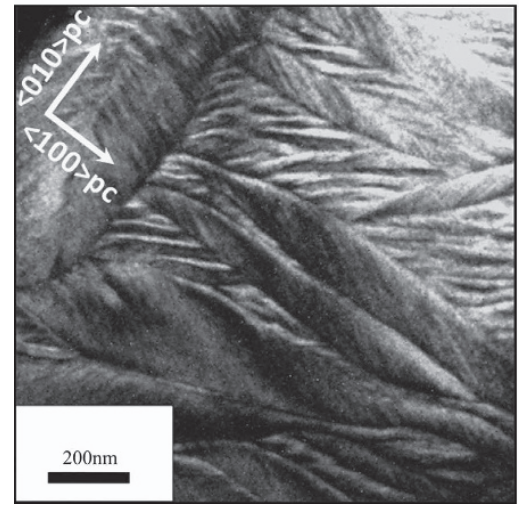

b

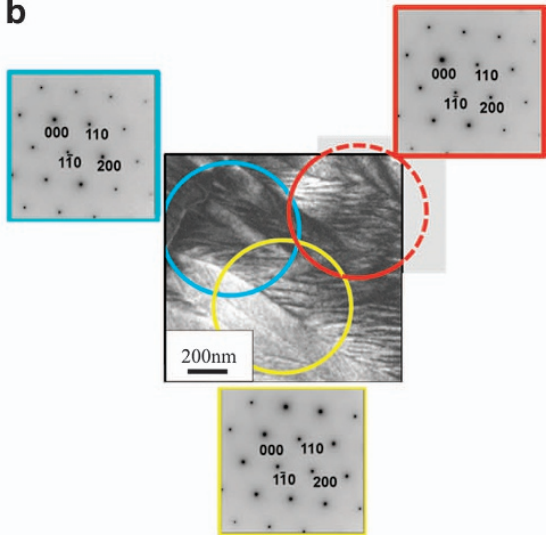

Figure 9 HRTEM image of feathery ferroelastic nanodomains nested inside a single micron-size ferroelectric domain in PFT/PZT single-phase crystal. ${ }^{53}$ (a) Real-space HRTEM image; (b) reciprocal-space Bragg scattering from each of three regions circled.

mm2 (two mirror planes and a twofold axis). Toledano and Toledano ${ }^{56}$ consider such a case of an antiferromagnetic material (with specific space group $\left.\mathrm{Pca}_{1} 1^{\prime}\right)$. There are four irreducible corepresentations $\Gamma_{j}$, which transform like the magnetism components $L_{3 \mathrm{z}}, M_{\mathrm{z}}, L_{2 \mathrm{z}}$ and $L_{1 \mathrm{z}}$, where $L$ is sublattice antiferromagnetic magnetization and $M$ is weak ferro-magnetization. At the Neel temperature, antiferromagnetism produces spontaneous strain of both

$$
e_{x z}=\text { const. } L_{1 z}^{2} / C_{13} \text { and } e_{x y}=\text { const. } L_{2 z}^{2} / C_{12}
$$

where $C_{i j}$ are the elastic constants. This magnetoelastically induced shear strain lowers the crystallographic symmetry from orthorhombic to monoclinic at $T(\mathrm{Neel})$, from $\mathrm{Pca} 2_{1}$ to $\mathrm{Pb}(\mathrm{x})$. When this monoclinic strain is coupled to polarization $P$ via piezoelectric coupling, it can produce the kind of magnetoelastically induced polarization switching inferred for $\mathrm{Pb}\left(\mathrm{Fe}_{1 / 2} \mathrm{Ta}_{1 / 2}\right)_{\mathrm{x}}$ $\left(\mathrm{Zr}_{\mathrm{y}} \mathrm{Ti}_{1-\mathrm{y}}\right)_{1-\mathrm{x}} \mathrm{O}_{3}$. That is, the strain produced magnetically can create or facilitate ferroelectricity via piezoelectricity. However, a spontaneous strain component produced by magnetostriction does not always break the structural symmetry. If the magnetostriction in a $\mathrm{Pca}_{1} 1^{\prime}$ structure crystal is

$$
e_{x x}=-a L_{3 z}^{2} / C_{11} \text { ore }_{y y}=-b L_{3 z}^{2} / C_{22} \text { ore }_{z z}=-c L_{3 z}^{2} / C_{33}
$$

(induced by an irreducible representation that transforms like the identity representation $\Gamma_{1}$ ), then there is no symmetry breaking; the structure remains orthorhombic, and one can discuss only a bulk volume-magnetostriction that shrinks the lattice constants, a so-called isosymmetric transition.

Whether the monoclinic distortion occurs or not depends upon the stability of terms in the magnetic-free energy:

$$
F(\operatorname{mag})=a_{i}(T) L_{i}^{2}+c(T) M^{2}+b_{i}(T) L_{i}^{4}+d M^{4}+g_{i}(T) L_{i z}^{2}+\ldots
$$

where sums over repeated subscripts are implied.

If $c(T)$ vanishes first near $T(N)$, for example, as $(T-T(N))$, the transition is driven by exchange, and $\mathrm{Pca} 2_{1}$ lowers to $\mathrm{P} 2_{1}$ (both mirror planes are lost). If $a_{1}(T)$ vanishes first, $\mathrm{Pca} 2_{1}$ lowers to $\mathrm{Pb}$, losing a mirror plane and the twofold axis due to relativistic spin-orbit terms. If $a_{3}(T)$ vanishes first, there is no symmetry change. 
Thus, in $\mathrm{Pb}\left(\mathrm{Fe}_{1 / 2} \mathrm{Ta}_{1 / 2}\right)_{\mathrm{x}}\left(\mathrm{Zr}_{\mathrm{y}} \mathrm{Ti}_{1-\mathrm{y}}\right)_{1-\mathrm{x}} \mathrm{O}_{3}$, which exhibits short-range magnetic order up to about $400 \mathrm{~K}$, the long-range order sets in at $T(N)$ around $30-50 \mathrm{~K}$, depending upon Fe concentration, and dielectric anomalies occur at $T(N)$. These are probably due to spontaneous magnetostriction, and an orthorhombic-monoclinic distortion is expected in zero field. Consequently, it is reasonable to invoke magnetostriction in its switching dynamics at higher temperatures in an applied field $H$.

PFN. Magnetic and electrical studies of PFN and of PFN mixed with $\mathrm{PbMg}_{1 / 2} \mathrm{~W}_{1 / 2} \mathrm{O}_{3}$ by Peng et al. ${ }^{40-42}$ revealed several important things: PFN can be prepared in a single phase, without any pyrochlore or other minor phases; it exhibits relaxor behavior characterized by antiferromagnetic clusters and by two equations-a standard Vogel-Fulcher Equation describing a characteristic relaxation frequency

$$
f=f_{0} \exp \left\{\left(-E_{\mathrm{a}}\right) /\left[k_{\mathrm{B}}\left(T_{\mathrm{m}}-T_{\mathrm{f}}\right)\right]\right\}
$$

where $T_{m}$ is the temperature of the maximum dielectric constant and freezing temperature $T_{f}=270 \mathrm{~K}$; and a semi-empirical expression for maximum dielectric constant

$$
[\varepsilon(\max ) / \varepsilon(\text { baseline })]-1=\left(T-T_{\mathrm{m}}\right)^{\gamma} /(2 \Delta)^{2}
$$

where $\gamma=1.9$ (such relaxor exponents are generally $=2.0$ ).

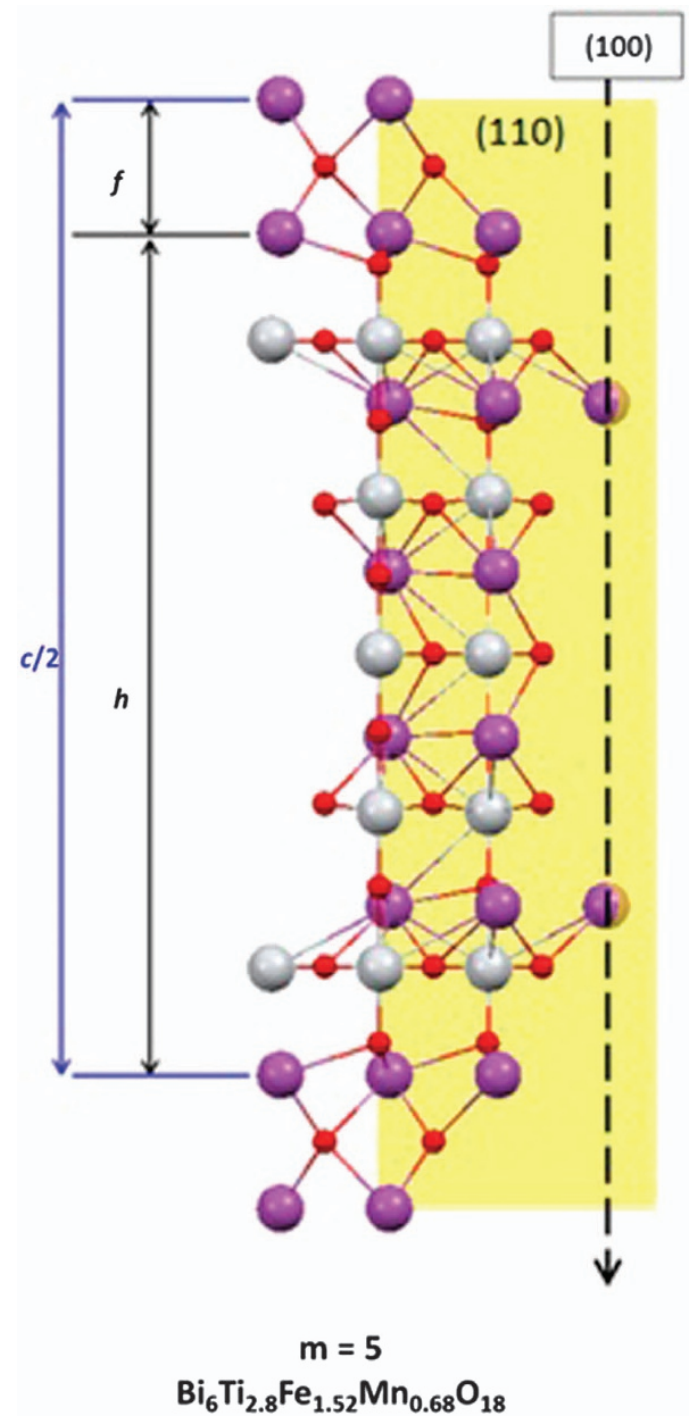

Figure 10 Aurivilius structure for $n=5$ perovskite blocks between each pair of $\mathrm{Bi}_{2} \mathrm{O}_{2}$ planes. ${ }^{67}$
Rather surprisingly, recent Russian work by Raevski et al. ${ }^{43}$ on PFN shows that its relaxor properties are extrinsic. This disagrees strongly with the model of Peng et al.

\section{Aurivilus-phase ferrites, cobaltates, and manganites}

Ferroelectricity. The Aurivilius-phase ferroelectrics typified by $\mathrm{Sr}_{2} \mathrm{BiTa}_{2} \mathrm{O}_{9}$ were first discovered by Smolenskii's group in Leningrad in the late 1950s, who studied a large number of the family members, replacing $\mathrm{Sr}$ with $\mathrm{Pb}$ or $\mathrm{Ba}$ and $\mathrm{Ta}$ with $\mathrm{Nb}$ or Ti. The structure (Figures 10 and 11) consists of $\mathrm{ABO}_{3}$ perovskite blocks with $n=2,3,4,5$ or more sharing faces, separated by $\mathrm{Bi}_{2} \mathrm{O}_{2}$ planes. $\mathrm{Sr}_{2} \mathrm{BiTa}_{2} \mathrm{O}_{9}$ is an example with $n=2 ; \mathrm{Bi}_{4} \mathrm{Ti}_{3} \mathrm{O}_{12}$ has $n=3 .^{57}$ $\mathrm{SrBi}_{4} \mathrm{Ti}_{4} \mathrm{O}_{15}$ has $n=4 .^{58-61} \mathrm{Ba}_{2} \mathrm{Bi}_{4} \mathrm{Ti}_{5} \mathrm{O}_{18}$ has $n=5$ (Figure10). The latter materials brought early attention because of their very fast $n s$ switching speeds. ${ }^{62}$ Stable compounds with up to $\mathrm{O}_{27}$ (nine blocks per layer) are known. For odd- $n$, the structures are ferroelectric, whereas for $n$ even, they are mostly antiferroelectric as emphasized by Tachiki et $a l^{63}$ and by Reaney and Domjanovic $^{64}$ and shown in the superlattice reflections of the e-beam scattering of Scott and Ross. ${ }^{65} \mathrm{Bi}_{2} \mathrm{O}_{2}$ planes have a key role in device performance as ferroelectric memories: Fatigue (decrease in switched charge with repetitive polarization reversals) arises largely from oxygen vacancies in $\mathrm{ABO}_{3}$ perovskite ferroelectrics such as $\mathrm{BaTiO}_{3}$ or $\mathrm{PbTiO}_{3}$, but in the Aurivilius phase materials the oxygen vacancies occur primarily in the $\mathrm{Bi}_{2} \mathrm{O}_{2}$ planes, where they have negligible effect on the polarization of Ti-O or Nb-O or Ta-O covalent bonds. ${ }^{66,67}$

Magnetoelectric Aurivilius phases. The realization that magnetic ions could be substituted into Aurivilius-phase ferroelectrics came independently from several sources, but it was ambiguous in these studies whether the magnetism $M$ arose from small minor phases; even a tiny percentage by weight could produce the measured values of $M$. Keeney et al. ${ }^{68}$ have carried out careful measurements on an $n=5$ Aurivilius structure in which the B-site in each perovskite block is $70 \%$ filled with $\mathrm{Fe}$ and $30 \%$ with Co: they find that $\mathrm{Bi}_{5} \mathrm{Ti}_{3} \mathrm{Fe}_{0.7} \mathrm{Co}_{0.3} \mathrm{O}_{15}$ films and $\mathrm{Bi}_{5} \mathrm{Ti}_{3} \mathrm{Fe}_{0.7} \mathrm{Mn}_{0.3} \mathrm{O}_{15}$ are complicated because of the presence of $\mathrm{Fe}$ - and/or Co-rich secondary spinel-phases. Even in tiny

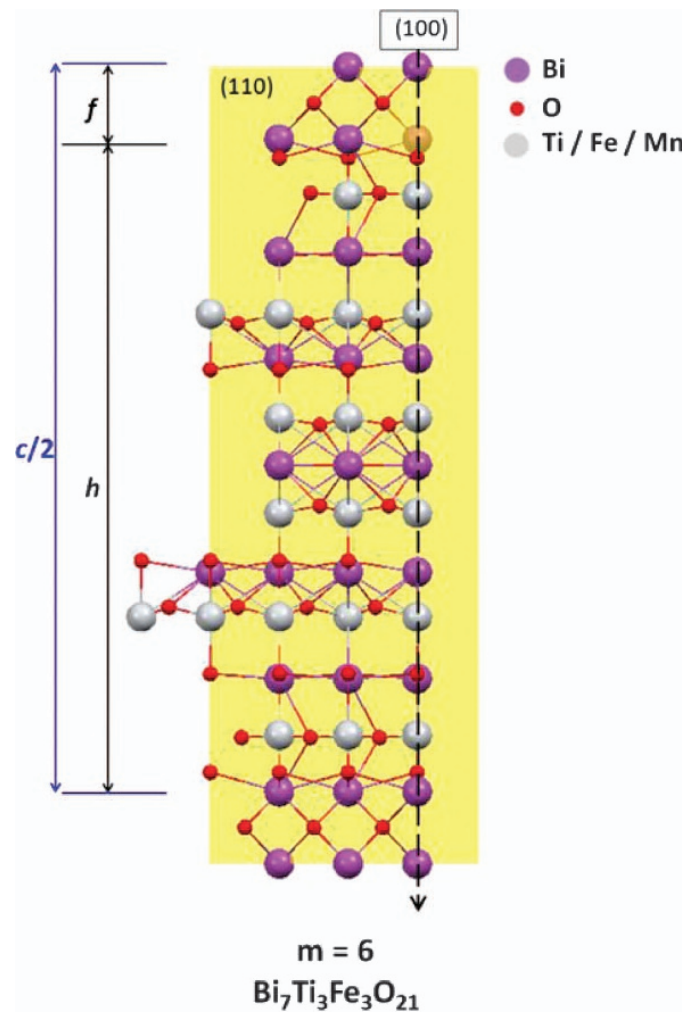

Figure 11 Aurivilius structure for $n=6$ perovskite blocks between each pair of $\mathrm{Bi}_{2} \mathrm{O}_{2}$ planes. ${ }^{68}$ 

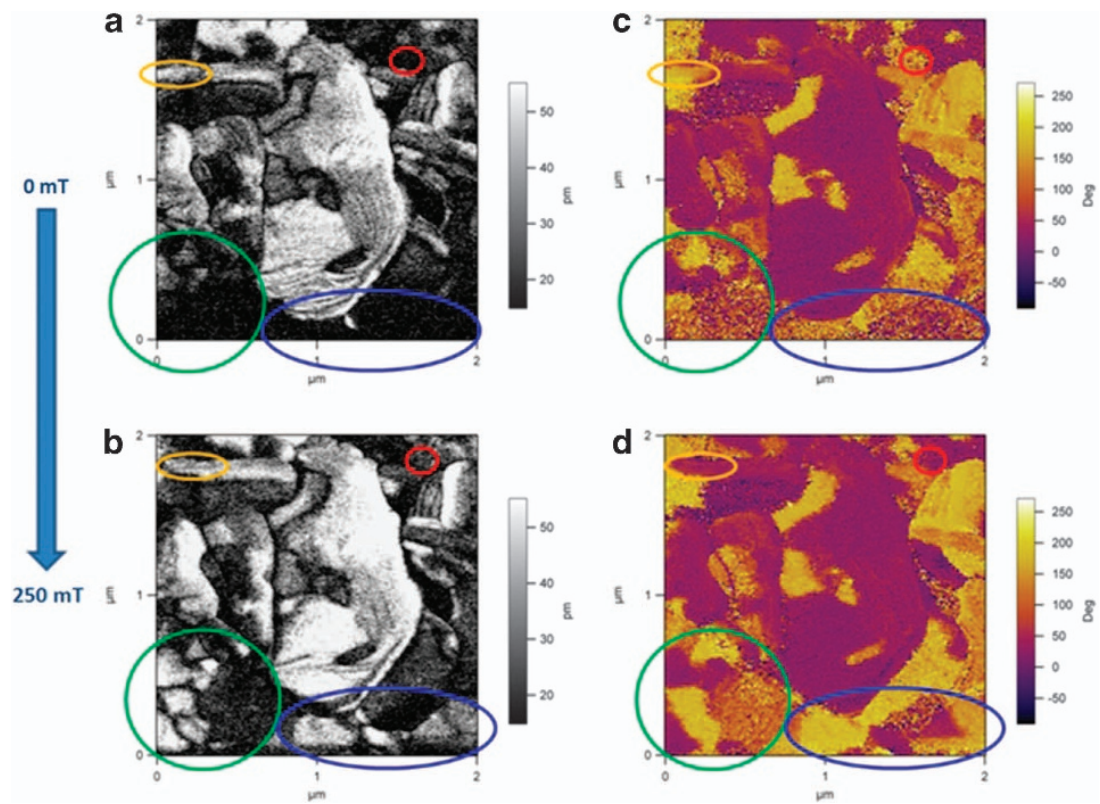

Figure 12 Polarization switching in $\mathrm{Ba}_{6} \mathrm{Ti}_{2.8} \mathrm{Fe}_{1.52} \mathrm{Mn}_{0.68} \mathrm{O}_{18} \cdot{ }^{68}$ Panels (a) and (c) are topographic images; (b) and (d), polarization images; (a) and (b) have $H=0$; (b) and (d), $H=250 \mathrm{mT}$.

percentages $(<<1 \%)$ these magnetic spinels contribute most or all of the room temperature magnetic response, whereas pure $\mathrm{Bi}_{5} \mathrm{Ti}_{3} \mathrm{Fe}_{0.7} \mathrm{Co}_{0.3} \mathrm{O}_{15}$ is not ferromagnetic. However, in subsequent work this year (2013), they report extensive studies $^{69}$ on a room-temperature ferroelectric-ferromagnet of this family with $n=6: \mathrm{Ba}_{6} \mathrm{Ti}_{2.8} \mathrm{Fe}_{1.52} \mathrm{Mn}_{0.68} \mathrm{O}_{18}$ (Figure 11). In addition, the $n=5$ Aurivilius structure (Figure 10) $\mathrm{Bi}_{4.4} \mathrm{Nd}_{0.85} \mathrm{Ti}_{3} \mathrm{Fe}_{0.5} \mathrm{Co}_{0.5} \mathrm{O}_{15}$ was characterized carefully and so were the related family members $\mathrm{Bi}_{6} \mathrm{Ti}_{2.6} \mathrm{Fe}_{1.77} \mathrm{Mn}_{0.63} \mathrm{O}_{18}$ (the 1.77 Fe-fraction occurs when all $\mathrm{Mn}$ ions are converted to $\mathrm{Mn}^{+4}$ ) and $\mathrm{Bi}_{7} \mathrm{Ti}_{3} \mathrm{Fe}_{3} \mathrm{O}_{21}$. Figure 12 reproduces their polarization switching in a magnetic field of $H=0.25 \mathrm{~T}$ at room temperature. Values of $M$ as large as $6 \mathrm{emu} \mathrm{cc}^{-1}$ were measured in zero field. However, as the electrical measurements were via AFM/PFM, no numerical values were obtained for polarization $P$ or dielectric constant $\varepsilon$. As a result, it is premature to comment on the kinds of devices that might be possible; however, as most ferroelectric Aurivilius-phase oxides exhibit remnant polarizations $P>>1 \mu \mathrm{Ccm}^{-2}$, it is reasonable to conclude that these new materials might make RAM elements.

\section{Hexaferrites}

Background. The discovery of a low-field room-temperature multiferroic z-type hexaferrite was made in 2010 by Kimura's group in Osaka. ${ }^{70,71}$ They found the highest performance in $\mathrm{Sr}_{3} \mathrm{Co}_{2} \mathrm{~F}_{24} \mathrm{O}_{41}$, whose structure is shown below (Figure 13). Hexaferrites occur in three complicated families, so-called $\mathrm{x}$-type, $\mathrm{y}$-type and z-type. The $\mathrm{y}$-type is represented by $\mathrm{Ba}_{2} \mathrm{Mg}_{2} \mathrm{Fe}_{12} \mathrm{O}_{22}$, but generally these have lower transition temperatures ${ }^{72,73}$ and cannot be roomtemperature devices. These and other related materials exhibit room temperature magnetic control of electric polarization direction but not all are magnetoelectric switches. They exhibit good device numbers $\left(P=25 \mu \mathrm{Ccm}^{-2}\right.$ and coercive field $\left.E=20 \mathrm{kV} \mathrm{cm}^{-1}\right)$, but not all produce switching of $P$ with applied $H$ or switching of $M$ with applied $E$ in zero field $H$.

Comparisons for device purposes. Hexaferrites offer great advantages in the size of switched polarization in comparison with cycloidic spin structures. In general, multiferroic materials based upon cycloidic spin arrangements produce very weak polarizations (typically $\mathrm{nCm}^{-2}$-or Coulombs hectare ${ }^{-1}$ !), whereas about $1 \mu \mathrm{C} \mathrm{cm}^{-2}$ (a thousand times more) is required for the sense amplifiers in a conventional RAM to discriminate between a 1 and a 0 in the Boolean algebra of modern computers. In addition, most multiferroics to date function at only cryogenic temperatures (for example, $28 \mathrm{~K}$ for $\mathrm{TbMnO}_{3}$ ). Even $\mathrm{CuO}$ works only below $230 \mathrm{~K}$ (not at room temperature) and has negligibly small polarization $P$ for use as a RAM. In comparison, $\mathrm{Sr}_{3} \mathrm{Co}_{2} \mathrm{~F}_{24} \mathrm{O}_{41}$ exhibits plausible device parameters for temperatures up to $500 \mathrm{~K}$, as shown in Figure 14, which nicely incorporates both military-use specifications ('mil specs') and also automotive industry specifications. Unfortunately, the samples initially reported ${ }^{70}$ were relatively fine-grained ceramics, so that detailed measurements of anisotropy and tensor parameters were not possible; however, more recently good single-crystal work was reported by Chun et al. ${ }^{71}$ In the $\mathrm{PbTa}_{1 / 2} \mathrm{Fe}_{1 / 2} \mathrm{O}_{3}$ family discussed elsewhere in this review, this was also the case, but individual single crystals were cut via focused-ion beam from 1.0-micron diameter single grains to permit studies of individual nanocrystals. However, it must be emphasized that $\mathrm{Sr}_{3} \mathrm{Co}_{2} \mathrm{~F}_{24} \mathrm{O}_{41}$ is not a (linear) magnetoelectric; although it demonstrates low-field magnetoelectric effects at room temperature, it shows no polarization at zero magnetic field and therefore is not a bilinear magnetoelectric.

\section{Chromia $\mathrm{Cr}_{2} \mathrm{O}_{3}$}

It would be remiss not to mention $\mathrm{Cr}_{2} \mathrm{O}_{3}$. Although it is neither ferroelectric nor ferromagnetic, its antiferroelectric properties do indeed permit a linear magnetoelectric effect and switching through Equation (9):

$$
G(T, P, L)=\alpha_{j k} P_{j} L_{k}
$$

where $L$ is the subattice magnetic magnetism (spin canting is not required), and $P$ is the sublattice antiferroelectric polarization. Note that $P$ and $L$ do not have to arise from the same ion. (Parenthetically, we note that this is important in the general case of multiferroics: The argument of Hill (Spaldin) about ferromagnetism and ferroelectricity being mutually disadvantageous assumes that they arise from the same bonds-such as covalent Ti-O bonds ${ }^{66}$ - whereas in general the ferroic phenomena can arise from different ions or bonds, such as the ferroelectric $\mathrm{Bi}$ ions and magnetic $\mathrm{Fe}$ ions in $\mathrm{BiFeO}_{3}$. Ironically, systems such as $\mathrm{PbFe}_{1 / 2} \mathrm{Ta}_{1 / 2} \mathrm{O}_{3}$ that have both ferroelectricity and ferromagnetism arising from the B-site Fe-ions are simple oxide perovskites that one might expect to satisfy Hill's mutual exclusion rule.)

Chromia was historically important from the prediction of Dzyaloshinskii ${ }^{74}$ and the verification by Astrov, ${ }^{75}$ and the fact that Folen et al. ${ }^{76}$ found the converse effect and that it functions up to $260 \mathrm{~K}$. More recent work by Kleemann's group claims it provides functional magnetoelectric memory devices well above room temperature. ${ }^{77}$ However, chromia generates much less interest than other multiferroics, because it is more complicated to address (READ/WRITE) antiferroelectrics and antiferromagnets than with 
a $\mathrm{M}$-type $\left[(\mathrm{Ba}, \mathrm{Sr}) \mathrm{Fe}_{12} \mathrm{O}_{19}\right]$
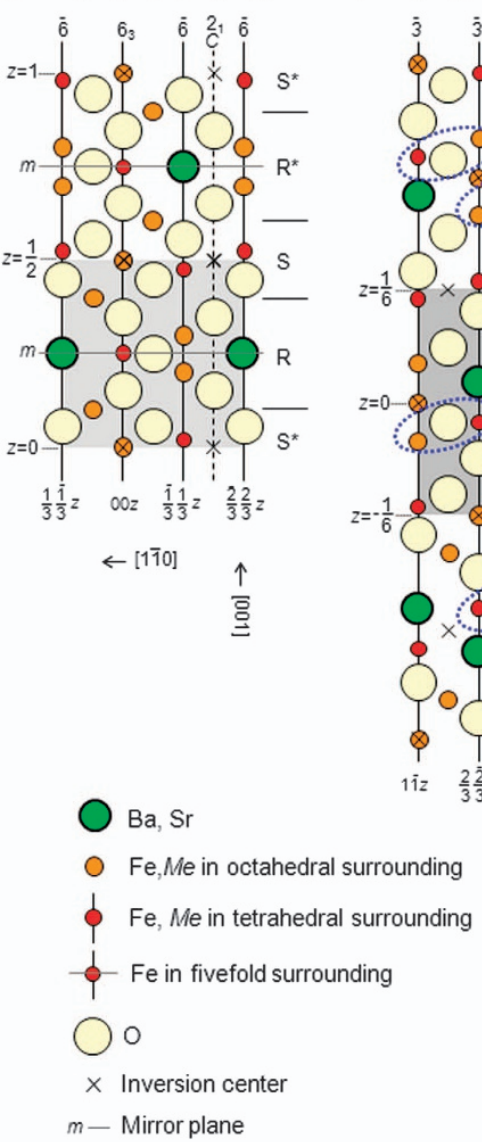

Figure 13 Structure of $z$-type hexaferrite $\mathrm{Sr}_{3} \mathrm{CO}_{2} \mathrm{~F}_{24} \mathrm{O}_{41} \cdot{ }^{69}$

ferroelectric/ferromagnets. Some recent commercial interest has been reported (Phillips), but no prototype devices are shown.

\section{SUMMARY AND PERSPECTIVE}

Multiferroic single-phase magnetoelectrics have been extraordinarily interesting from the point of view of basic science: They combine nicely two heretofore separate topics of magnetism and ferroelectricity. This is quite timely because only a generation ago ferroelectricity was often regarded as semi-classical physics with balls and sticks, whereas magnetism was acknowledged to be fully quantum mechanical. Recent work with Berry-phase descriptions of ferroelectrics and density functional techniques have put the two topics together in a way that permits a single kind of calculation to address both phenomena in a coherent description. ${ }^{78,79}$ The topic is also appealing, because it is limited to exactly those very low-symmetry crystals that avoided attention by serious physicists in earlier years (with a few notable exceptions such as Hans Schmid ${ }^{80}$ in Geneva and Smolenskii in Leningrad).

Some scientists believe that a single-phase room-temperature multiferroic magnetoelectric will combine the best aspects of MRAMs and FRAMs: voltage-driven (as opposed to current-driven), lowpower, ultra-fast (sub-ns READ/WRITE operations), and so on. To me, this is still quite remote. In most cases, the speeds are too slow, the switched charge is too small and the temperature range impractical. Moreover, although the switching magnetic fields involved of $0.25-0.30 \mathrm{~T}$ may seem modest, they are orders of magnitude larger than the mT MRAM devices; MRAMs can function with the very small fields generated by current pulses passing under each bit on the chip, but it will be impractical to generate fields of order $1 \mathrm{~T}$ that way. Larger switched polarizations are also problematical; they may involve a trade-off to strain-moderated slow switching, and in my opinion the Aurivilius-phase material from Cork is the leading new challenger to $\mathrm{BiFeO}_{3}$. But by comparison, multi-layer magnetoelectric devices already work well commercially. ${ }^{81}$ So where is the breakthrough for single-phase multiferroics?

To end on a more optimistic note: not all multiferroic magnetoelectric device applications are for RAMs. Great progress has been made with electrically switched magnetic tunnel junctions ${ }^{82}$ and with voltage-driven Mott transitions. ${ }^{83}$ So it would be an unnecessarily pessimistic mistake to conclude that the future is limited in this way. Probably the future is quite promising, in fact; and we should not limit our thinking to the 1985-era matrix architecture of switchedcapacitor MRAMs and FRAMs. For example, both Pyatakov et al. ${ }^{84}$ and Prosandeev and Bellaiche ${ }^{85}$ have published methods of addressing magnetic vortex domains or ferroelectric vortex domains via electric fields for memory applications. Such vortex domains have advantages for memory storage because of their very small size, and these new papers help solve the subtle question of how to address such vortex domains.

Another possible avenue for better room-temperature multiferroics is better processing. It is well known from the early work of Setter and Cross $^{86}$ that the structure of ferroelectric $\mathrm{PbSc}_{1 / 2} \mathrm{Ta}_{1 / 2} \mathrm{O}_{3}$ ('PST') can have anything from perfectly ordered $\mathrm{Sc}$ and $\mathrm{Ta}$ ions to perfectly random B-site occupancy, dependent solely upon the annealing procedure. This produces different structure and properties and 


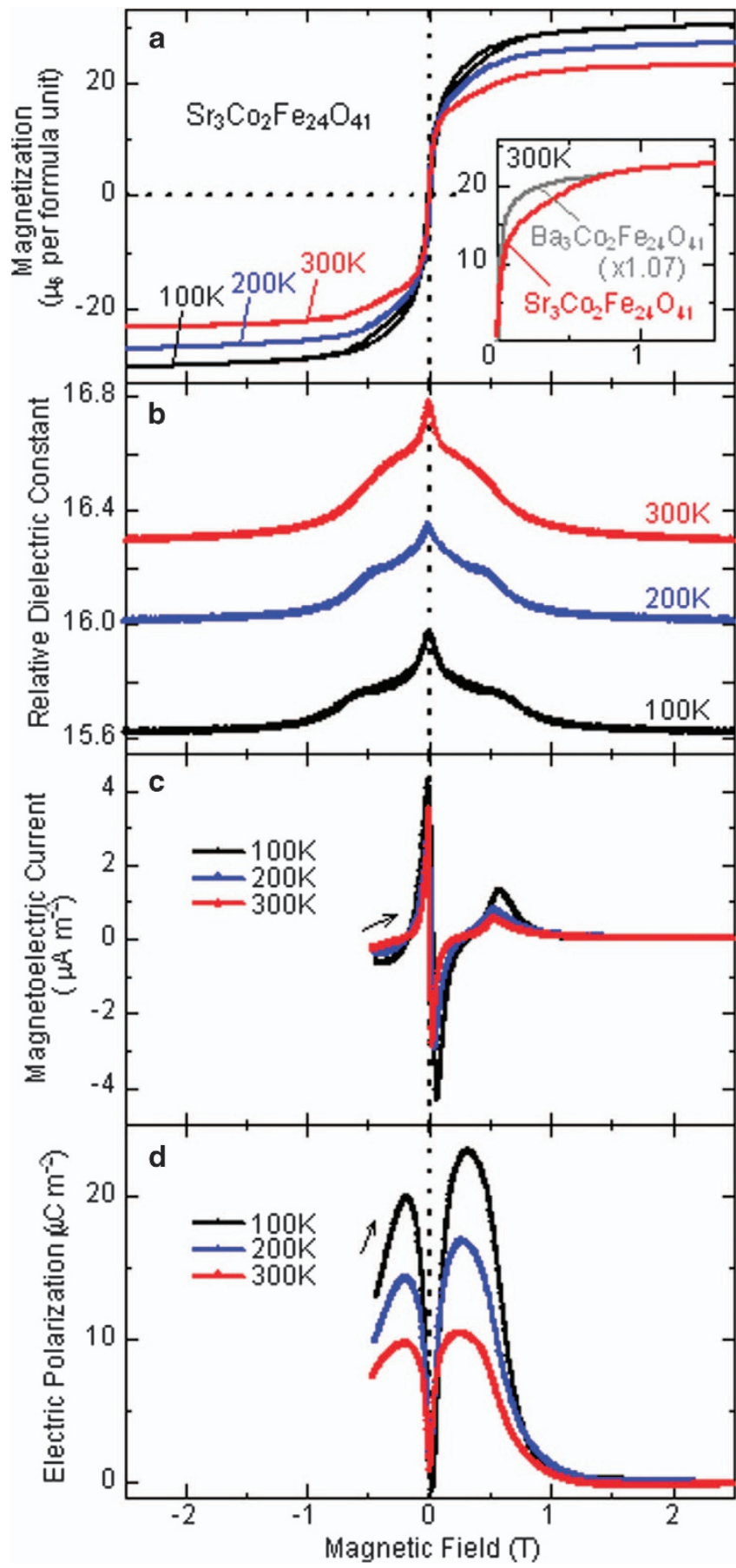

Figure 14 Magnetic switching of electrical polarization $\mathrm{P}(H)$ in the $z$-type hexaferrite $\mathrm{Sr}_{3} \mathrm{C}_{2} \mathrm{~F}_{24} \mathrm{O}_{41} .69$

even a different number of phases. ${ }^{87} \mathrm{PbFe}_{1 / 2} \mathrm{Ta}_{1 / 2} \mathrm{O}_{3}$ is very similar to $\mathrm{PbSc}_{1 / 2} \mathrm{Ta}_{1 / 2} \mathrm{O}_{3}$, but we know almost nothing about how to control its $\mathrm{B}$-site occupancy; this may be a route to enhanced magnetoelectric performance. It seems likely that either making the $\mathrm{Fe} / \mathrm{Ta}$ ions fully ordered at the B-site or making them completely random will enhance magnetoelectric properties (and operating temperatures?). At present, the B-site ions are clustered and neither random nor fully ordered. For further detailed analyses of multiferroic magnetoelectrics, readers are referred to a longer review by the present $^{\text {author. }}{ }^{88}$
1 Aizu, K. Possible species of ferromagnetic, ferroelectric, and ferroelastic crystals. Phys. Rev. B 2, 754-772 (1970).

2 Toledano, J. C. Ferroelasticity. Ann. Telecommun. 29, 249-271 (1974).

3 Schmid, H. \& Trooster, J. M. Mossbauer effect and optical evidence for new phase transitions in $\mathrm{Fe}-\mathrm{Cl}, \mathrm{Fe}-\mathrm{Br}$, Fe-I, Co-Cl and $\mathrm{Zn}-\mathrm{Cl}$ boracite. Sol. St. Commun. 5, 31-35 (1967).

4 Scott, J. F. \& Araujo, C. A. Ferroelectric memories. Science 246, 1400-1405 (1989).

5 Scott, J. F. Ferroelectric Memories (Springer, Heidelberg, Germany, 2000).

6 Gajek, M., Bibes, M., Fusil, S., Bouzehouane, K., Fontcuberta, J., Barthelemy, A. E. \& Fert, A. Tunnel junctions with multiferroic barriers. Nat. Mater. 6, 296-302 (2007).

7 Hernandez, B. A., Chang, K. S., Fisher, E. R. \& Dorhout, P. K. Sol-gel template synthesis and characterization of $\mathrm{BaTiO}_{3}$ and $\mathrm{PbTiO}_{3}$ nanotubes. Chem. Mater. 14, 480-482 (2002)

8 Luo, Y., Szafraniak, I., Zakharov, N. D., Nagarajan, V., Steinhart, M., Wehrspohn, R. B., Wendorff, J. H., Ramesh, R. \& Alexe, M. Nanoshell tubes of ferroelectric lead zirconate titanate and barium titanate. Appl. Phys. Lett. 83, 440-442 (2003).

9 Morrison, F. D., Luo, Y., Szafraniak, I., Nagarajan, V., Wehrspohn, R. B., Steinhart, M., Wendroff, J. H., Zakharov, N. D., Mishina, E. D., Vorotilov, K. A., Sigov, A. S., Nakabayashi, S., Alexe, M., Ramesh, R. \& Scott, J. F. Ferroelectric Nanotubes; arXiv:cond-mat/0303609 (2003).

10 Morrison, F. D., Ramsay, L. \& Scott, J. F. High aspect-ratio piezoelectric strontiumbismuth-tantalate nanotubes. J. Phys. Cond. Mat. 15, L527-L532 (2003).

11 Scott, J. F., Fan, H. J., Kawasaki, S., Banys, J., Ivanov, M., Krotkus, A., Macutkevic, J., Blinc, R., Laguta, V. V., Cevc, P., Liu, J. S. \& Kholkin, A. L. Terahertz emission from tubular $\mathrm{Pb}(\mathrm{Zr}, \mathrm{Ti}) 0-3$ nanostructures. Nano. Lett. 8, 4404-4409 (2008).

12 Kawasaki, S., Fan, H.-J., Catalan, G., Morrison, F. D., Tatsuta, T., Tsuji, O. \& Scott, J. F. Solution-process coating of vertical $\mathrm{ZnO}$ nanowires with ferroelectrics. Nanotechnology 19, 375302 (2008)

13 Kawasaki, S., Catalan, G., Fan, H. J., Saad, M. M., Gregg, J. M., Correa-Duarte, M. A. Rybczynski, J., Morrison, F. D., Tatsuta, T., Tsuji, O. \& Scott, J. F. Conformal oxide coating of carbon nanotubes. Appl. Phys. Lett. 92, 053109 (2008).

14 Fan, H. J., Kawasaki, S., Gregg, J. M., Langner, A., Leedham, T. \& Scott, J. F. Concentric metallic-piezoelectric microtube arrays. MRS Symp. Proc. 1071, 201-206 (2008).

15 Miyake, M. Scott, J. F., Lou, X. J., Morrison, F. D., Nonaka, T., Motoyama, S., Tatsuta, T. \& Tsuji, O. Submicron three-dimensional trenched electrodes and capacitors for DRAMs and FRAMs: fabrication and electrical testing. J. Appl. Phys. 104, 064112 (2008).

16 Kumar, A., Shivareddy, S. G., Correa, M., Resto, O., Choi, Y., Cole, M. T., Katiyar, R. S., Scott, J. F., Amaratunga, G. A. J., Lu, H. D. \& Gruverman, A. Ferroelectric-carbon nanotube memory devices. Nanotechnology 23, 165702 (2012).

17 Pirovano, A., Lacaita, A. L., Benvenuti, A., Pellizzer, F. \& Bez, R. Electronic switching in phase change memories. IEEE Trans. Elec. Dev. 51, 452-459 (2004).

18 Greenemeier, L. Japanese satellite first to use magnetic memory. Sci. Am. 298 (2008).

19 Brown, W. F., Hornreich, R. M. \& Shtrikman, S. Upper bound on magnetoelectric susceptibility. Phys. Rev. 168, 574-579 (1968).

20 Dzyaloshinskii, I. E. Magnetoelectric to multiferroic phase transitions. EPL 96, 17001 (2010).

21 Wang, J., Neaton, J. B., Zheng, H., Nagarajan, B., Nagarajan, V., Ogale, S. B., Liu, B., Viehland, D., Vaithyanathan, V., Schlom, D. G., Waghmare, U. V., Spaldin, N. A., Rabe, K. M., Wuttig, M. \& Ramesh, R. Epitaxial $\mathrm{BiFeO}_{3}$ multiferroic thin film heterostructures. Science 299, 1719-1722 (2003).

22 Catalan, G. \& Scott, J. F. Physics and applications of bismuth ferrite. Adv. Mater. 21, 2463-2485 (2009).

23 Smolenskii, G. A. \& Yudin, V. M. Weak ferromagnetism of some $\mathrm{BiFeO}_{3}$ $\mathrm{Pb}\left(\mathrm{Fe}_{0.5} \mathrm{Nb}_{0.5}\right) \mathrm{O}_{3}$ perovskites. Sov. Phys. Sol. St. 6, 2936-2942 (1965).

24 Rusakov, D. A., Abakumov, A. M., Yamaura, K., Abakumov, A. M., Yamaura, K., Belik, A. A., Van Tendeloo, G. \& Takayama-Muromachi, E. Structural evolution of the $\mathrm{BiFeO}_{3}-\mathrm{LaFeO}_{3}$ system. Chem. Mater. 23, 285-292 (2011).

25 Catalan, G., Sardar, K., Church, N. S., Scott, J. F., Harrison, R. J. \& Redfern, S. A. T. Effect of chemical substitution on the Neel temperature of multiferroics $\mathrm{Bi}_{1}-\mathrm{x} \mathrm{CaxFeO}_{3}$. Phys. Rev. B 79, 212415 (2009).

26 Sardar, K., Hong, J.-W. Catalan, G., Biswas, P. K., Lees, M. R., Walton, R. I., Scott, J. F. \& Redfern, S. A. T. Structural, spectroscopic, magnetic and electrical characterization of Ca-doped polycrystalline bismuth ferrite, $\mathrm{Bi}^{-}-\mathrm{xCaxFeO}_{3}-\mathrm{x} / 2(x<0.1)$. J. Phys. Cond. Mat 24, 045905 (2012).

27 Kimura, T., Sekio, Y., Nakamura, H., Siegrist, T. \& Ramirez, A. P. Cupric oxide as an induced-multiferroic with high-TC. Nat. Mater. 7, 291-294 (2008).

28 Babkevich, P., Poole, A., Johnson, R. D., Roessli, B., Prabhakaran, D. \& Boothroyd, A. T. Electric field control of chiral magnetic domains in the high-temperature multiferroic CuO. Phys. Rev. B 85, 134428 (2012).

29 Johnson, S. L., De Souza, R. A., Staub, U., Beaud, P., Mohr-Vorobeva, E., Ingold, G., Caviezel, A., Scagnoli, V., Schlotter, W. F., Turner, J. J., Krupin, O., Lee, W. S., Chuang, Y. D., Patthey, L., Moore, R. G., Lu, D., Yi, M., Kirchmann, P. S., Trigo, M., Denes, P., Doering, D., Hussain, Z., Shen, Z. X., Prabhakaran, D. \& Boothroyd, A. T. Femtosecond dynamics of the collinear-to-spiral antiferromagnetic phase transition in CuO. Phys. Rev. Lett. 108, 037203 (2012)

30 Scagnoli, V., Staub, U., Bodenthin, Y., Staub, U., Bodenthin, Y., De Souza, R. A., Garcia-Fernandez, M., Garganourakis, M., Boothroyd, A. T., Prabhakaran, D. \& Lovesey, S. W. Observation of orbital currents in CuO. Science 332, 696-698 (2011). 
31 Joly, Y., Collins, S. P., Grenier, S., Tolentino, H. C. N., Helio, C. N. \& De Santis, M Birefringence and polarization rotation in resonant x-ray diffraction. Phys. Rev. B 86 220101 (2012).

32 Sanchez, D. A., Ortega, N., Kumar, A., Roque-Malherbe, R., Polanco, R., Scott, J. F. R. \& Katiyar, R. S. Symmetries and multiferroic properties of novel room-temperature magnetoelectrics: lead iron tantalate-lead zirconate titanate (PFT/PZT). AIP Adv. 1, 042169 (2011).

33 Sanchez, D. A., Kumar, A., Ortega, N., Katiyar, R. S. \& Scott, J. F. Near room temperature relaxor multiferroic. Appl. Phys. Lett. 97, 202910 (2010).

34 Pirč, R., Blinc, R. \& Scott, J. F. Mesoscopic model of a system possessing both relaxor ferroelectric and relaxor ferromagnetic properties. Phys. Rev. B 79, 214114 (2009).

35 Levstik, A., Bobnar, V., Filipic, C., Holc, J., Kosec, M., Blinc, R., Trontelj, Z. \& Jaglicic Z. Magnetoelectric relaxor. Appl. Phys. Lett. 91, 012905 (2007).

36 Kumar, A., Sharma, G. L., Katiyar, R. S., Pirč, R., Blinc, R. \& Scott, J. F. Magnetic control of large room temperature polarization. J. Phys. Cond. Mat. 21, 382204 (2009).

37 Sanchez, D. A., Ortega, N., Kumar, A., Sreenivasulu, G., Katiyar, R. S., Scott, J. F., Evans, D. M. \& Gregg, J. M. Room-temperature single phase multiferroic magnetoelectrics: $\mathrm{Pb}(\mathrm{Fe}, \mathrm{M})_{x}(\mathrm{Zr}, \mathrm{Ti})_{(1-x)} \mathrm{O}_{3}[\mathrm{M}=\mathrm{Ta}, \mathrm{Nb}]$. J. Appl. Phys. 113 074105 (2013).

38 Correa, M., Kumar, A., Priya, S., Katiyar, R. S. \& Scott, J. F. Phonon anomalies and phonon-spin coupling in oriented $\mathrm{PbFe}_{0.5} \mathrm{Nb}_{0.5} \mathrm{O}_{3}$ thin films. Phys. Rev. B 83, 014302 (2011).

39 Kumar, A., Scott, J. F. \& Katiyar, R. S. Biferroic relaxors. Appl. Phys. Lett. 99, 042907 (2011).

40 Kumar, A., Katiyar, R. S., Premnath, R. N., Rinaldi, C. \& Scott, J. F. Strain-induced artificial multiferroicity in $\mathrm{Pb}\left(\mathrm{Zr}_{0.53} \mathrm{Ti}_{0.47}\right) \mathrm{O}_{3} / \mathrm{Pb}\left(\mathrm{Fe}_{0.66} \mathrm{~W}_{0.33}\right) \mathrm{O}_{3}$ layered nanostructure at ambient temperature. J. Mater. Sci. 44, 5113-5119 (2009).

41 Peng, W., Lemee, N., Karkut, M., Dkhil, B., Shvartsman, V. V., Borisov, P., Kleemann, W., Holc, J., Kosec, M. \& Blinc, R. Spin-lattice coupling in multiferroic $\mathrm{PbFe}_{1 / 2} \mathrm{Nb}_{1 / 2} \mathrm{O}_{3}$ thin films. Appl. Phys. Lett. 94, 012509 (2009).

42 Peng, W., Lemee, N., Dellis, J. L., Shvartsman, V. V., Borisov, P., Kleemann, W. Trontelj, Z., Holc, J., Kosec, M., Blinc, R. \& Karkut, M. G. Epitaxial growth and magnetoelectric relaxor behavior in $0.8 \mathrm{PbFe}_{1 / 2} \mathrm{Nb}_{1 / 2} \mathrm{O}_{3-0.2} \mathrm{PbMg}_{1 / 2} \mathrm{~W}_{1 / 2} \mathrm{O}_{3}$. Appl. Phys. Lett. 95, 132507 (2009).

43 Peng, W., Lemee, N., Holc, J., Kosec, M., Blinc, R. \& Karkut, M. G. Epitaxial growth and structural characteristics of $\mathrm{PbFe}_{1 / 2} \mathrm{Nb}_{1 / 2} \mathrm{O}_{3}$ thin films. J. Mag. Mag. Mat. 321 1754-1757 (2009).

44 Raevski, I. P., Kubrin, S. P., Raevskaya, S. I., Prosandeev, S. A., Malitskaya, M. A. Titov, V. V., Sarychev, D. A., Blazhevich, A. V. \& Zakharchenko, I. N. Dielectric and mossbauer studies of ferroelectric and magnetic phase transitions in A-site and B-site substituted multiferroic $\mathrm{PbFe}_{0 .} \mathrm{Nb}_{0.5} \mathrm{O}_{3}$. IEEE Trans. Ultrason. Ferroelec. Freq. Cntrl. 59, 1872-1878 (2012)

45 Boggs, J., Bersuker, I. B., Quan, L., Shi, J. Z. \& Li, J. M. First-principles study on the multiferroelectricity of Mn doped BaTi03. J. Synth. Crystals 42, 533-536 (2013).

46 Levstik, A., Filipic, C. \& Holc, J. The magnetoelectric coefficients of PbFe1/2W1/2)03 and $0.8 \mathrm{PbFe}_{1 / 2} \mathrm{Nb}_{1 / 2} \mathrm{O}_{3-0.2} \mathrm{PbMg}_{1 / 2} \mathrm{~W}_{1 / 2} \mathrm{O}_{3}$. J. Appl. Phys. 103, 066106 (2008).

47 Kempa, M., Kamba, M., Savinov, S., Maryško, M., Frait, M., Vaněk, Z., Tomczyk, P. \& Vilarinho, P. M. Bulk dielectric and magnetic properties of PFW-PZT ceramics: absence of magnetically switched-off polarization. J. Phys. Cond. Mat 22, 445902 (2010).

48 Lee, D., Yang, S. M., Jo, Y. \& Song, T. K. Room-temperature multiferroic properties of $\mathrm{Pb}\left(\mathrm{Zr}_{0.57} \mathrm{Ti}_{0.43}\right) \mathrm{O}_{3}-\mathrm{Pb}\left(\mathrm{Fe}_{0.67} \mathrm{~W}_{0.33}\right) \mathrm{O}_{3}$ solid-solution epitaxial thin films. J. Korean Phys. Soc. 57, 1914-1918 (2010).

49 Levstik, A., Filipic, C., Bobnar, V., Drnovsek, S., Holc, J. \& Kosec, M. Polaron conductivity mechanism in $0.5 \mathrm{~Pb}\left(\mathrm{Zr}_{0.575} \mathrm{Ti}_{0.425}\right) \mathrm{O}_{3-0.5} \mathrm{~Pb}\left(\mathrm{Fe}_{0.67} \mathrm{~W}_{0.33}\right) \mathrm{O}_{3}$. Physica $B$ 405, 4271-4273 (2010)

50 Fischer, K. H. \& Hertz, J. A. Spin Glasses (Cambridge University Press, Cambridge, UK, 1991).

51 Dussan, S., Kumar, A., Scott, J. F., Priya, S. \& Katiyar, R. S. Room temperature multiferroic effects in superlattice nanocapacitors. Appl. Phys. Lett. 97, 252902 (2010).

52 Dussan, S., Kumar, A., Scott, J. F. \& Katiyar, R. S. Effect of electrode resistance on dielectric and transport properties of multiferroic superlattice: an impedance spectroscopy study. AIP Adv. 2, 032136 (2013).

53 Kumar, A., Rivera, I., Katiyar, R. S. \& Scott, J. F. Multiferroic $\mathrm{Pb}\left(\mathrm{Fe}_{0.66} \mathrm{~W}_{0.33}\right) 0.80$ $\mathrm{TiO} .20 \mathrm{O}_{3}$ thin films: a room-temperature relaxor ferroelectric and weak ferromagnetic. Appl. Phys. Lett. 92, 132913 (2008).

54 Evans, D. M., Schilling, A., Kumar, A., Katiyar, R. S., Gregg, J. M. \& Scott, J. F. Magnetic switching of ferroelectric domains at room temperature in multiferroic PZTFT. Nat. Commun. 4, 1534 (2013).

55 Scott, J. F. Self-assembly and switching of ferroelectrics and multiferroics. EPL 25, 331001 (2013).

56 Toledano, J. C. \& Toledano, P. The Landau Theory of Phase Transitions (World Scientific, Singapore, 1987).

57 Garg, A., Barber, Z. H., Dawber, M., Scott, J. F., Snedden, A. \& Lightfoot, P. Orientation dependence of ferroelectric properties of pulsed-laser-ablated Bi4-xNdxTi3012 films. Appl. Phys. Lett. 83, 2414-2416 (2003).

58 Subbarao, E. C. Ferroelectricity in mixed bismuth oxides withy layer-type structure. $J$. Chem. Phys. 34, 695-701 (1961).

59 Subbarao, E. C. Ferroelectricity in Bi4Ti3012 and its solid solutions. Phys. Rev. 122, 804-809 (1961)
60 Smolenskii, G. A., Agranovskaya, A. I. \& Isupov, V. A. New ferroelectrics of complex composition: $\mathrm{Pb}_{2} \mathrm{MgWO}_{6}, \mathrm{~Pb}_{3} \mathrm{Fe}_{2} \mathrm{WO}_{9}$, and $\mathrm{Pb}_{2} \mathrm{FeTaO}_{6}$. Sov. Phys. Sol. St. 1, $907-$ 908 (1959).

61 Smolenskii, G. A., Isupov, V. A. \& Agranovskaya, A. A. Ferroelectrics of the oxygenoctahedra type with layered structure. Sov. Phys. Sol. St. 3, 651-655 (1961).

62 Fang, P. H. \& Fatuzzo, E. Switching properties in ferroelectrics of family $\mathrm{Ba}_{4} \mathrm{BaM}-$ ${ }_{2} \mathrm{TiM}+{ }_{1} \mathrm{O}_{3} \mathrm{M}+2$. J. Phys. Soc. Jpn. 17, 238-245 (1962).

63 Tachiki, M., Yamamuro, K. \& Kobayashi, T. Optical characterization of Srm$3 \mathrm{Bi}_{4} \mathrm{TimO}_{3 \mathrm{~m}+3}(\mathrm{~m}=4,5,6)$ thin films grown by pulsed laser deposition method Jpn. J. Appl. Phys. 38, L719-L721 (1996).

64 Reaney, I. M. \& Damjanovic, D. Crystal structure and domain-wall contributions to the piezoelectric properties of strontium bismuth titanate ceramics. J. Appl. Phys. 80, 4223-4225 (1996).

65 Scott, J. F. \& Ross, F. M. New results on layer-structure perovskite ferroelectric thinfilm memories. Ferroelectrics 201, 43-53 (1997).

66 Cohen, R. E. Origin of ferroelectricity in perovskite oxides. Nature 358, 136-138 (1992)

67 De Araujo, C. A. P., Cuchiaro, J. D., McMillan, L. D., Scott, M. C. \& Scott, J. F. Fatigue-free ferroelectric capacitors with platinum electrodes. Nature $\mathbf{3 7 4}, 627-629$ (1995)

68 Keeney, L., Kulkarni, S., Deepak, N., Schmidt, M., Petkov, N., Zhang, P. F., Cavill, S. Roy, S., Pemble, M. E. \& Whatmore, R. W. Room temperature ferroelectric and magnetic investigations and detailed phase analysis of Aurivillius phase $\mathrm{Bi}_{5} \mathrm{Ti}_{3} \mathrm{Fe}_{0.7}$ $\mathrm{Co}_{0.3} \mathrm{O}_{15}$ thin films. J. Appl. Phys. 112, 052010 (2013).

69 Keeney, L., Kulkarni, S., Deepak, N., Keeney, L., Maity, T., Schmidt, M., Amann, A Deepak, N., Petkov, N., Roy, S., Pemble, M. E. \& Whatmore, R. W. Magnetic fieldinduced ferroelectric switching in multiferroic aurivillius phase thin films at room temperature. J. Am. Ceram. Soc. 96, 2339-2357 (2013).

70 Kitagawa, Y., Hiraoka, Y., Honda, T., Ishikura, T., Nakamura, H. \& Limura, T. Low-field magnetoelectric effect at room temperature. Nat. Mater. 9, 797-802 (2010).

71 Chun, S. H., Chai, Y. S., Jeon, B. G., Kim, H. J., Oh, Y. S., Kim, I. G., Kim, H. B., Jeon, B. J., Haam, S. Y., Park, J. Y., Lee, S. H., Chung, J. H., Park, J. H. \& Kim, K. H. Electric field control of nonvolatile four-state magnetization at room temperature. Phys. Rev. Lett. 108, 177201 (2012).

72 Kimura, T., Lawes, G. \& Ramirez, A. P. Electric polarization rotation in a hexaferrite with long-wavelength magnetic structures. Phys. Rev. Lett. 94, 137201 (2005).

73 Taniguchi, K., Abe, N., Ohtani, S., Umetsu, H. \& Arima, T. Ferroelectric polarization reversal by a magnetic field in multiferroic Y-type hexaferrite $\mathrm{Ba}_{2} \mathrm{Mg}_{2} \mathrm{Fe}_{12} \mathrm{O}_{22}$. Appl. Phys. Express. 1, 031301 (2008).

74 Dzyaloshinskii, I. E. On the magneto-electrical effect in antiferromagnets. Sov. Phys. JETP 10, 628-629 (1960).

75 Astrov, D. N. The magnetoelectric effect in antiferromagnts. Sov. Phys. JETP 11, 708 709 (1960).

76 Folen, V. J., Rado, G. T. \& Stadler, E. W. Anisotropy of the magnetoelectric effect in Cr203. Phys. Rev. Lett. 6, 607-608 (1961).

77 Borisov, P., Hochstrat, A., Shvartsman, V. V., Kleemann, W., Eimuller, T. \& Rodriguez, A. F. Thin $\mathrm{Cr}_{2} \mathrm{O}_{3}$ films for magnetoelectric data storage deposited by reactive e-beam evaporation. Ferroelectrics 370, 147-152 (2008).

78 Resta, R. Macroscopic polarization in crystalline dielectrics-the geometric phase approach. Rev. Mod. Phys 66, 899-915 (1994)

79 Vanderbilt, D. H. Soft self-consistent pseudopotentials in a generalized eigenvalue formalism. Phys. Rev. B 41, 7892-7895 (1990).

80 Ascher, E., Rieder, H., Schmid, H. \& Stossel, H. Some properties of ferromagnetoelectric nickel-iodine boracite $\mathrm{Ni}_{3} \mathrm{~B}_{7} \mathrm{O}_{13}$ I. J. Appl. Phys. 37, 1404-1409 (1966).

81 Wang, Y., Finkel, P., Li, J. \& Viehland, D. Mechanical loss and magnetoelectric response in magnetostrictive/interdigitated-electrode/piezoelectric laminated resonators. J. Appl. Phys. 113, 124508 (2013)

82 Bibes, M. \& Barthelemy, A. Multiferroics: towards a magnetoelectric memory. Nat. Mater. 7, 425-426 (2008).

83 Scherwitzl, R., Gariglio, S., Gabay, M., Zubko, P., Gibert, M. \& Triscone, J. M Metal-insulator transition in ultrathin LaNiO3 films. Phys. Rev. Lett. 106, 246403 (2011)

84 Pyatakov, A. P., Meshkov, G. A. \& Zvezdin, A. K. Electric polarization of magnetic textures: new horizons of micromagnetism. J. Mag. Mag. Mat 324, 3551-3554 (2012).

85 Prosandeev, S. \& Bellaiche, L. Hypertoroidal moment in complex dipolar structures. J. Mater. Sci. 44, 5235-5248 (2009).

86 Setter, N. \& Cross, L. E. The role of B-site cation disorder in diffuse phase-transition behavior of perovskite ferroelectrics. J. Appl. Phys 51, 4356-4360 (1980).

87 Dawber, M., Rios, S., Scott, J. F., Zhang, Q. \& Whatmore, R. W. Cryogenic studies of manganese-doped lead scandium tantalate thin films: phase transitions or domain wall dynamics? AIP Conf. Proc. 582, 1-10 (2001)

88 Catalan, G. \& Scott, J. F. in Magnetoelectric Coupling and Multiferroic Materials Multifunctional Oxide Heterostructures (eds Tsymbal, E. Y. et al.) Ch. 2, pp 38-98 (Oxford University Press, Oxford, UK, 2012).

(c) (i) $\Theta$ This work is licensed under a Creative Commons Attribution-NonCommercial-NoDerivs 3.0 Unported License. To view a copy of this license, visit http://creativecommons. org/licenses/by-nc-nd/3.0/ 


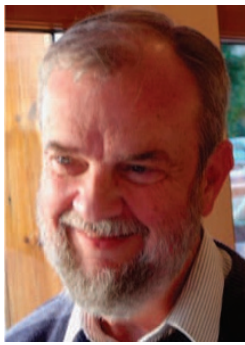

James F Scott is a Professor of Physics and the Director of Research at the Cavendish Laboratory, Cambridge University, Cambridge, UK. An American by birth, he previously served as Dean in two Australian Universities (RMIT, Melbourne, and UNSW, Sydney) before coming to England in 1999. He was educated at Harvard and Ohio State University (physics) and initially worked at Bell Telephone Laboratories during 1966-71 in the Quantum Electronics research department (Murray Hill and Holmdel, New Jersey, USA) before taking a chair at the University of Colorado (1971-92). Author of more than 500 journal articles, he also published the most popular book on ferroelectrics ('Ferroelectric Memories,' Springer, Heiderlberg, 2000), which has been translated into Japanese (Springer Japan, Tokyo) and Chinese (Tsinghua Press, Beijing) and served as a Chairman of the Board of Directors of Symetrix Corp. and Chairman of the Technical Board of Ramtron. He founded Symetrix Corporation with Carlos Araujo and Larry McMillan in 1984 but left the company in 1999. With 30000 citations, he is one of the most cited authors in ferroelectricity. Scott has spent several sabbatical stays in Asia, beginning in 1982 (Science University of Tokyo) and more recently as the SONY Visiting Professor (Atsugi/Yokohama) in 1997, and Nara Institute of Technology in 2001, with shorter stays in Osaka in 1981 and in Korea (Pohang) and China (Beijing, Nanjing, Shanghai). In 1981, he was among the first US scientists permitted to visit China, and that year he helped start the CUSPEA physics program between PRC and USA that brought Chinese PhD physics students to America. Scott was awarded the Monkasho Award from Japan in 2000, the Humboldt Prize from Germany in 1997, the Jozef Stefan gold Medal from Slovenia in 2009, the Materials Research Society (MRS) gold Medal from the USA in 2008 and elected to the Slovenian Academy of Sciences in 2011. He is also a Fellow of the Royal Society. 